\title{
Apoptosis in Candida biofilms exposed to amphotericin B
}

\author{
Correspondence \\ L. Julia Douglas \\ j.douglas@bio.gla.ac.uk
}

Received 4 September 2009

Accepted 3 November 2009

\author{
Rawya S. Al-Dhaheri and L. Julia Douglas \\ Division of Infection and Immunity, Faculty of Biomedical and Life Sciences, University of Glasgow, \\ Glasgow G12 800, UK
}

\begin{abstract}
Candida biofilms are resistant to a range of antifungal agents in current clinical use. The basis of this drug resistance is not clear, but in some cases it could be due to the presence of a small number of drug-tolerant or persister cells. In this study, specific staining methods were used to investigate the existence of persisters and apoptosis in Candida biofilms subjected to different concentrations of amphotericin B. Fluorescein diacetate staining revealed the presence of persisters in biofilms of one of two strains of Candida albicans tested, and in biofilms of Candida krusei and Candida parapsilosis. Caspase activity, indicative of apoptosis, was detected with SRFLICA and (aspartyl) ${ }_{2}$-rhodamine 110 fluorochrome-based staining reagents in all of these biofilms. The general inhibitor of mammalian caspases, Z-VAD-FMK, when used at a low concentration $(2.5 \mu \mathrm{M})$, increased the viability of drug-treated biofilms up to 11.5-fold ( $P$ $<0.001 \%)$. Seven specific caspase inhibitors had different effects on C. albicans biofilm viability, but inhibitors of caspases-1, $-9,-5,-3$ and -2 all significantly increased cell survival (40-fold, 8-fold, 3.5-fold, 1.9-fold and 1.7-fold, respectively). However, histone deacetylase (HDA) inhibitors enhanced the activity of amphotericin B for biofilms of all three Candida species. Sodium butyrate and sodium valproate, for example, when added concurrently with amphotericin B, completely eliminated biofilm populations of C. albicans. Overall, our results demonstrate an apoptotic process in amphotericin-treated biofilms of three Candida species. They also indicate that HDA inhibitors can enhance the action of the drug and in some cases even eradicate persister subpopulations, suggesting that histone acetylation might activate apoptosis in these cells.
\end{abstract}

\section{INTRODUCTION}

Opportunistic fungal pathogens of the genus Candida are known to be important agents of hospital-acquired infection. Many of these infections involve the formation of adherent biofilms on the surfaces of catheters, prosthetic heart valves and other medical devices (Kojic \& Darouiche, 2004). Biofilm organisms are phenotypically different from planktonic cells and, characteristically, are significantly less susceptible to antimicrobial agents, making the management of implant infections difficult. Although recent evidence suggests that some Candida biofilms show decreased viability when treated with caspofungin and related echinocandins in vitro (Choi et al., 2007; Katragkou et al., 2008), they are resistant to most other clinically important antifungal agents, such as amphotericin B, fluconazole and voriconazole (Douglas, 2003; Hawser \& Douglas, 1995; Ramage et al., 2005).

The mechanisms that protect micro-organisms in biofilms from antimicrobial agents are poorly understood (Douglas,

Abbreviations: $\mathrm{D}_{2} \mathrm{R}$, (aspartyl) ${ }_{2}$-rhodamine 110; DIC, differential interference contrast; HDA, histone deacetylase.
2003; Ramage et al., 2005). One proposal that has gained considerable support in recent years involves the existence of a small number of drug-tolerant or persister cells - usually $1 \%$ or less of the overall population - that neither grow nor die in the presence of microbicidal agents (Keren et al., 2004; Lewis, 2000, 2001, 2007). Persisters can withstand drug concentrations substantially above the MIC and represent specialized survivor cells that are phenotypic variants of the wild-type rather than mutants. It has been suggested that if micro-organisms exposed to antibiotics or other antimicrobial agents undergo a type of programmed cell death or apoptosis, persisters would be variants in which this process has been disabled (Lewis, 2000). Persisters have been identified in a variety of bacterial species (Lewis, 2007) and their existence in biofilms of Candida albicans has also been reported recently (Khot et al., 2006; LaFleur et al., 2006). However, it appears that not all strains of $C$. albicans produce persisters (Al-Dhaheri \& Douglas, 2008). Moreover, although persisters have been found in biofilms of Candida krusei and Candida parapsilosis, they were absent from biofilms formed by Candida glabrata and Candida tropicalis (Al-Dhaheri \& Douglas, 2008). In contrast to bacterial species tested, 
planktonic cultures (exponential or stationary phase) of Candida species seem to be devoid of persisters (AlDhaheri \& Douglas, 2008; LaFleur et al., 2006).

Programmed cell death responses have been described in a variety of fungi after exposure of the organisms to a range of conditions, such as weak acid stress, oxidative stress or UV irradiation. Fungal cells dying in this way display a number of markers characteristic of apoptosis, including the exposure of phosphatidylserine at the plasma membrane and the degradation of DNA (Hamann et al., 2008; Mazzoni \& Falcone, 2008; Ramsdale, 2008). Recent studies have demonstrated that planktonically grown cells of $C$. albicans undergo apoptosis when subjected not only to weak acid stress but also to amphotericin B (Phillips et al., 2003). In mammalian cells, acquisition of an apoptotic morphology depends on the activation of cysteinedependent aspartate-specific proteases (caspases). Functional analyses of genes in Saccharomyces cerevisiae have revealed similarities between fungal apoptosis and apoptosis in mammalian cells, and a homologue of mammalian caspases, YCA1 (Yeast Caspase 1), has been identified (Madeo et al., 2002). The caspase superfamily consists of three families; YCA1 belongs to the metacaspase family of enzymes, which are found in plants, fungi and protozoa (Uren et al., 2000). Overexpression of YCA1 (also known as MCA1) increases hydrogen-peroxide-induced caspase-like activity and apoptosis in S. cerevisiae (Madeo et al., 2002). Recently, a homologue of YCA1, CaMCA1, has been identified in C. albicans; deletion of the CaMCA1 gene results in decreased caspase activity (Cao et al., 2009).

Histone deacetylase (HDA) inhibitors, such as valproic acid, trichostatin A and butyric acid, are known to induce apoptosis in mammalian cells (Kawagoe et al., 2002; Medina et al., 1997). Valproic acid also induces YCA1dependent apoptosis in S. cerevisiae (Mitsui et al., 2005; Sun et al., 2007). In C. albicans, HDA inhibitors have been reported to enhance sensitivity to azoles and other antifungal agents (Mai et al., 2007; Smith \& Edlind, 2002), to inhibit adhesion and serum-induced germ-tube formation (Noverr \& Huffnagle, 2004; Simonetti et al., 2007), and to promote colony-type switching (Klar et al., 2001; Srikantha et al., 2001). Histone acetylation and deacetylation play important roles in eukaryotic gene regulation. Acetylation is generally associated with activation, whereas lack of acetylation tends to correlate with repression; these two processes work together to achieve appropriate levels of transcription (Sterner \& Berger, 2000).

In this study, we have used specific staining methods to investigate the existence of persisters and apoptosis in biofilm cells of C. albicans, C. krusei and C. parapsilosis subjected to different concentrations of amphotericin B. We have also determined the effect of apoptosis-inhibiting compounds (general and specific caspase inhibitors) and apoptosis-inducing compounds (HDA inhibitors) on the survival of biofilm cells exposed to the drug.

\section{METHODS}

Organisms. Three Candida species were used in this study. C. albicans GDH 2346, C. parapsilosis AAHB 4479 and C. krusei (Glasgow strain) are clinical isolates whose origins are described elsewhere (Hawser \& Douglas, 1994). C. albicans SC5314 was kindly provided by N. A. R. Gow, University of Aberdeen, Aberdeen, Scotland. All organisms were maintained on slopes of Sabouraud dextrose agar (Difco). Fresh slopes were prepared at 2 month intervals from long-term stocks held in $50 \%$ glycerol at $-70{ }^{\circ} \mathrm{C}$.

Medium and culture conditions. Organisms were grown in yeast nitrogen base (YNB) medium (Difco) containing $50 \mathrm{mM}$ glucose (YNB glucose). Batches of medium $(50 \mathrm{ml}$ in $250 \mathrm{ml}$ Erlenmeyer flasks) were inoculated from culture slopes and incubated at $37^{\circ} \mathrm{C}$ in an orbital shaker at 60 r.p.m. Cells were harvested after $24 \mathrm{~h}$ and washed twice in $0.15 \mathrm{M}$ PBS ( $\mathrm{pH}$ 7.2). Before use in biofilm experiments, washed cell suspensions were standardized to an optical density of 0.8 at $520 \mathrm{~nm}$.

Caspase inhibitors, HDA inhibitors, amphotericin B and pepstatin A. Stock solutions $(14.7 \mathrm{mM})$ of the general caspase inhibitor, Z-VAD-FMK (Calbiochem), were prepared in DMSO. Seven specific caspase inhibitors were also used. They were supplied by the manufacturers (caspase inhibitor set III; Calbiochem) as $2 \mathrm{mM}$ solutions in DMSO and consisted of: caspase-1 inhibitor VI (ZYVAD-FMK); caspase-2 inhibitor I (Z-VDVAD-FMK); caspase-3 inhibitor II (Z-DEVD-FMK); caspase-5 inhibitor I (Z-WEHD-FMK); caspase-6 inhibitor I (Z-VEID-FMK); caspase-8 inhibitor II (Z-IETDFMK); caspase-9 inhibitor I (Z-LEHD-FMK). Stock solutions of the HDA inhibitors trichostatin A and apicidin (Calbiochem) were prepared in DMSO; HDA inhibitors sodium butyrate and sodium valproate (Sigma-Aldrich) were dissolved in sterile water. Stock solutions $\left(8 \mathrm{mg} \mathrm{ml}^{-1}\right)$ of amphotericin B (Sigma-Aldrich) were prepared in DMSO and stored at $-70{ }^{\circ} \mathrm{C}$. These solutions were further diluted in YNB glucose medium buffered to $\mathrm{pH} 7$ with $0.165 \mathrm{M}$ MOPS (Sigma-Aldrich) to give the final concentration required. Pepstatin A (Sigma-Aldrich) was dissolved at a concentration of $1 \mathrm{mg} \mathrm{ml}^{-1}$ in methanol containing $10 \%(\mathrm{v} / \mathrm{v})$ acetic acid.

Growth and amphotericin treatment of biofilms. Biofilms were formed on small discs (diameter $0.8 \mathrm{~cm}$ ) cut from polyvinyl chloride Faucher tubes (French gauge 36; Vygon) essentially as described previously (Baillie \& Douglas, 1999). The discs were placed in the wells of 24-well Costar tissue culture plates, and a standardized cell suspension $(80 \mu \mathrm{l})$ was applied to the surface of each one. Cells were allowed to adhere for $1 \mathrm{~h}$ at $37^{\circ} \mathrm{C}$. Non-adherent organisms were removed by washing, and the discs were incubated in wells of a fresh plate for $48 \mathrm{~h}$ at $37^{\circ} \mathrm{C}$, submerged in $1 \mathrm{ml} \mathrm{YNB}$ glucose medium to allow biofilm formation. The biofilms were then treated with amphotericin B at concentrations of 10,50 or $100 \mu \mathrm{g} \mathrm{ml}^{-1}$ as follows. Mature $(48 \mathrm{~h})$ biofilms were transferred to fresh wells, submerged in YNB glucose medium $(1 \mathrm{ml})$ containing the appropriate concentration of amphotericin and buffered to $\mathrm{pH} 7$ with $0.165 \mathrm{M}$ MOPS, and incubated at $37{ }^{\circ} \mathrm{C}$ for $24 \mathrm{~h}$. Control biofilms were incubated in buffered medium in the absence of amphotericin $\mathrm{B}$. After incubation, biofilm cells were harvested from the discs by scraping and vigorous vortexing, washed twice in PBS, and then resuspended in more PBS $(100 \mu \mathrm{l})$. Viable cell counts were determined by the standard procedure of serial dilution followed by plating on YNB agar containing $200 \mathrm{mM}$ glucose.

Live-dead cell staining with fluorescein. Fluorescein diacetate (Sigma-Aldrich) was used to distinguish living yeast cells, which are unstained, from dead cells, which fluoresce green. Mature (48 h) biofilms on catheter discs were submerged in $1 \mathrm{ml}$ buffered YNB glucose medium containing $100 \mu \mathrm{g}$ fluorescein diacetate $\mathrm{ml}^{-1}$ alone 
(control), or $100 \mu \mathrm{g}$ fluorescein diacetate $\mathrm{ml}^{-1}$ with $100 \mu \mathrm{g}$ amphotericin $\mathrm{B} \mathrm{ml}^{-1}$, and incubated for $24 \mathrm{~h}$ at $37^{\circ} \mathrm{C}$. The biofilm cells were then harvested, washed three times in PBS, resuspended in PBS $(300 \mu \mathrm{l})$, and viewed with a $\times 100$ oil immersion lens using a fluorescence microscope (Zeiss Axioimager M1).

SR-FLICA apoptosis detection assay. An SR-FLICA kit (Immunochemistry Technologies) was used to detect active caspase enzymes within biofilm cells. The SR-FLICA reagent was reconstituted in $50 \mu \mathrm{DMSO}$, as recommended by the manufacturers, to form a stock concentrate. The concentrate was further diluted with $200 \mu \mathrm{l}$ PBS to produce the working solution. Mature ( $48 \mathrm{~h}$ ) biofilms were submerged in buffered YNB glucose medium containing amphotericin B $\left(50 \mu \mathrm{g} \mathrm{ml}^{-1}\right)$ and incubated for $5 \mathrm{~h}$ or $24 \mathrm{~h}$ at $37^{\circ} \mathrm{C}$. The biofilms were washed gently in PBS and the cells were resuspended to a concentration of approximately $10^{7}$ cells $\mathrm{ml}^{-1}$. SRFLICA working solution $(10 \mu \mathrm{l})$ was then added to $200 \mu \mathrm{l}$ biofilm cell suspension and the mixtures were incubated for $1 \mathrm{~h}$ at $37{ }^{\circ} \mathrm{C}$ in the dark. The cells were washed twice using a wash buffer provided in the kit, resuspended in wash buffer $(300 \mu \mathrm{l})$ and examined under a $\times 100$ oil immersion lens using a fluorescence microscope (Zeiss Axioimager M1) with a bandpass filter (excitation $550 \mathrm{~nm}$, emission >580 nm). Apoptotic cells with active caspase enzymes fluoresced red.

\begin{abstract}
(Aspartyl $)_{2}$-rhodamine $110\left(D_{2} R\right)$ apoptosis detection assay. A CaspSCREEN kit (Biovision Research Products) was also used to detect caspase activity. Mature $(48 \mathrm{~h})$ biofilms were submerged in buffered YNB glucose medium containing amphotericin B $(50 \mu \mathrm{g}$ $\mathrm{ml}^{-1}$ ) and incubated for $24 \mathrm{~h}$ at $37^{\circ} \mathrm{C}$. Biofilm cells were washed gently in PBS and centrifuged to give a pellet $\left(10^{5}\right.$ cells $)$ that was resuspended in $\mathrm{D}_{2} \mathrm{R}$ incubation buffer $(0.3 \mathrm{ml})$. DTT $(1 \mathrm{M}, 3 \mu \mathrm{l})$ and $\mathrm{D}_{2} \mathrm{R}$ reagent $(1 \mu \mathrm{l})$ were then added and the mixture was incubated for $45 \mathrm{~min}$ at $37{ }^{\circ} \mathrm{C}$ in the dark. Resuspended cells were observed under a $\times 100$ oil immersion lens using a fluorescence microscope (Zeiss Axioimager M1) with a bandpass filter (excitation $488 \mathrm{~nm}$, emission $530 \mathrm{~nm}$ ). Apoptotic cells with active caspase enzymes fluoresced green.
\end{abstract}

Effect of caspase inhibitors. To investigate the effect of Z-VADFMK on biofilm growth and viability, $48 \mathrm{~h}$ biofilms were washed gently with PBS and submerged in YNB glucose medium $(1 \mathrm{ml})$ buffered with MOPS and containing different concentrations (2.5, 5, 10 and $20 \mu \mathrm{M}$ ) of Z-VAD-FMK. Control biofilms were transferred to buffered medium without Z-VAD-FMK. Biofilms were incubated for $24 \mathrm{~h}$ at $37{ }^{\circ} \mathrm{C}$ and then cells were harvested and their numbers determined by viable cell counts. To investigate the effect of Z-VADFMK on amphotericin B activity, the same procedure was followed except that $48 \mathrm{~h}$ biofilms were submerged in buffered YNB glucose medium containing Z-VAD-FMK $(2.5-20 \mu \mathrm{M})$ and amphotericin $\mathrm{B}$ $\left(50 \mu \mathrm{g} \mathrm{ml}^{-1}\right)$. The final concentration of DMSO in assay mixtures ranged from 0.12 to $0.26 \%$. Identical procedures were used to determine the effect of specific caspase inhibitors (caspase inhibitor set III) on biofilm growth and amphotericin B activity, except that these inhibitors were used at a single concentration of $2.5 \mu \mathrm{M}$.

Effect of HDA inhibitors. To investigate the effect of HDA inhibitors on biofilm growth and viability, mature $(48 \mathrm{~h})$ biofilms were washed gently with PBS and submerged in YNB glucose medium (1 $\mathrm{ml}$ ) buffered with MOPS and containing different concentrations (2, 8 or $32 \mu \mathrm{g} \mathrm{ml}^{-1} ; 2,8$ or $32 \mathrm{mM}$ for sodium butyrate) of HDA inhibitor. The biofilms were then incubated for a further $24 \mathrm{~h}$ at $37^{\circ} \mathrm{C}$. The final concentration of DMSO in all cases was less than $0.5 \%$; this concentration had no effect on biofilm viability. Control biofilms were incubated in medium without inhibitor. After incubation, biofilm cells were harvested and washed, and viable counts were determined as described above. To investigate the effect of HDA inhibitors on amphotericin B activity, the same procedure was followed except that $48 \mathrm{~h}$ biofilms were submerged in buffered YNB glucose medium containing amphotericin B $\left(50 \mu \mathrm{g} \mathrm{ml}^{-1}\right)$ and HDA inhibitor $\left(2,8\right.$ or $32 \mu \mathrm{g} \mathrm{ml}^{-1} ; 2,8$ or $32 \mathrm{mM}$ for sodium butyrate). Again, the final concentration of DMSO in the medium was less than $0.5 \%$. Control biofilms were incubated in medium without HDA inhibitor, or without both HDA inhibitor and amphotericin B.

\section{RESULTS AND DISCUSSION}

\section{Live-dead staining of biofilm cells with fluorescein diacetate}

Fluorescein diacetate was used to discriminate between living and dead biofilm cells; this dye specifically stains dead cells green. Biofilms ( $48 \mathrm{~h}$ ) of C. albicans (both strains), C. krusei and C. parapsilosis were treated with a high concentration $\left(100 \mu \mathrm{g} \mathrm{ml}^{-1}\right)$ of amphotericin B for $24 \mathrm{~h}$ at $37^{\circ} \mathrm{C}$, and the cells were then stained with fluorescein diacetate. With most of these biofilms, small numbers of unstained (live) cells were detected. These cells appeared to have a normal morphology and their numbers varied according to the Candida species under investigation (Fig. 1). C. parapsilosis biofilms contained more of the live cells than did biofilms of C. krusei or C. albicans GDH 2346. By contrast, no live cells were detected in biofilms of C. albicans SC5314 exposed to a high concentration of amphotericin B. Fluorescence was rarely observed in untreated, control cells (i.e. $72 \mathrm{~h}$ biofilm cells). On the assumption that the unstained cells represented drugtolerant persisters, these results with fluorescein staining confirm earlier viability measurements (Al-Dhaheri \& Douglas, 2008) which showed that persisters were present in biofilms of C. albicans GDH 2346, C. krusei and C. parapsilosis, but absent from biofilms of C. albicans SC5314.

\section{Caspase detection using a polycaspase SR-FLICA reagent}

The SR-FLICA reagent (fluorochrome-labelled inhibitor of caspase) was used to detect the presence of caspases in Candida biofilm cells. When the reagent enters a cell, any active caspases present will bind covalently to the peptide inhibitor sequence of SR-FLICA (VAD). As a result, the fluorescent label, sulforhodamine, is retained within the cell, which fluoresces red. Here, $48 \mathrm{~h}$ biofilms of C. krusei, C. parapsilosis and both strains of $C$. albicans were treated with amphotericin B $\left(50 \mu \mathrm{g} \mathrm{ml}^{-1}\right)$ for 5 or $24 \mathrm{~h}$. The cells were then labelled with the reagent and viewed under a fluorescence microscope.

Exposure of C. albicans biofilms to amphotericin B for $5 \mathrm{~h}$ resulted in relatively few cells that were stained with the SR-FLICA reagent (Fig. 2a, c). Considerably more stained cells $(93 \%)$ were seen in biofilms that had been exposed to the drug for $24 \mathrm{~h}$ (Fig. 2b, d), suggesting an ongoing process of apoptosis induction. After such treatment, higher numbers of apoptotic cells appeared to be present 
(a)
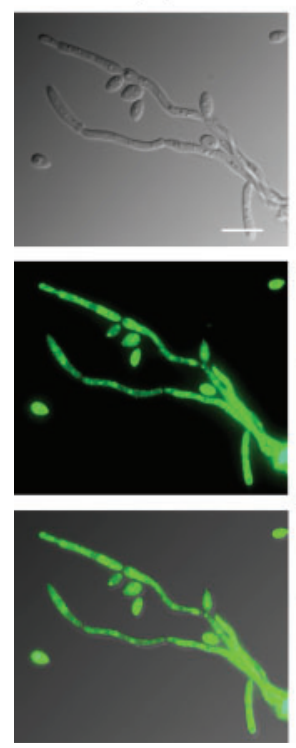

(b)
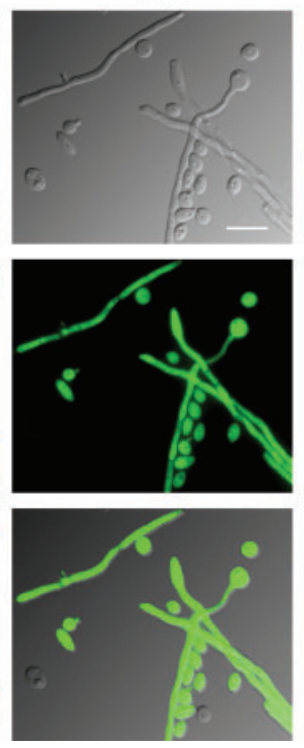

(c)
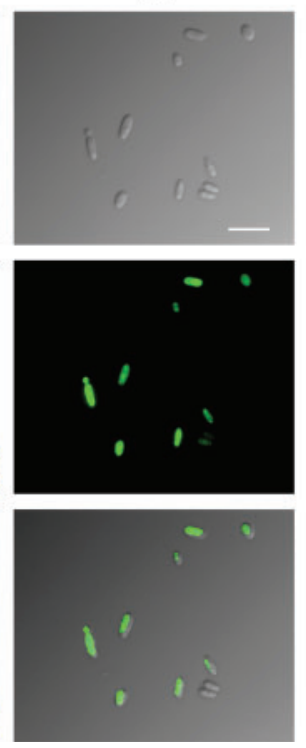

(d)
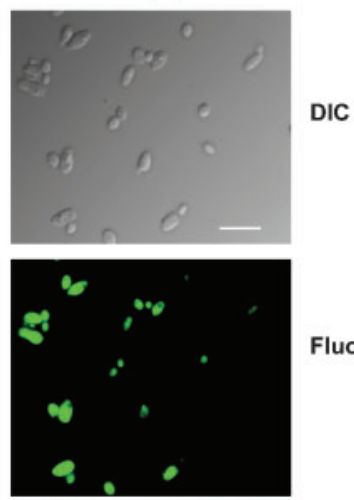

Fluorescence

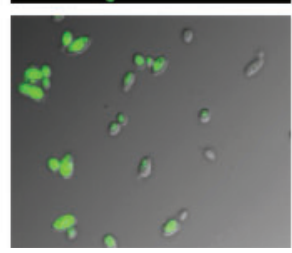

IC

Overlaid

Fig. 1. Live-dead staining of Candida biofilm cells with fluorescein diacetate. Biofilms ( $48 \mathrm{~h})$ were incubated with amphotericin $\mathrm{B}\left(100 \mu \mathrm{g} \mathrm{ml}^{-1}\right)$ and fluorescein diacetate $\left(100 \mu \mathrm{g} \mathrm{ml}^{-1}\right)$ for $24 \mathrm{~h}$ at $37^{\circ} \mathrm{C}$. Washed, resuspended biofilm cells were then examined by fluorescence microscopy. Differential interference contrast (DIC), fluorescence and overlaid images are shown of C. albicans SC5314 (a), C. albicans GDH 2346 (b), C. krusei (c) and C. parapsilosis (d). Dead cells show green fluorescence. Bars, $13 \mu \mathrm{m}$.

in biofilms of C. albicans (both strains) (Fig. 2b, d) and C. krusei (Fig. 2e) than in biofilms of C. parapsilosis (Fig. 2f).

In C. albicans growing planktonically, exposure of the organism to a variety of environmental stresses, and to amphotericin B or farnesol, is known to produce characteristics typical of apoptosis. These include externalization of phosphatidylserine, chromatin condensation, accumulation of reactive oxygen species, DNA degradation and caspase activation (Cao et al., 2009; Phillips et al., 2003; Shirtliff et al., 2009). For example, a single-cell death assay was used to show that a majority of amphotericintreated cells were nonviable and impermeable to propidium iodide. Apoptotic changes induced by the drug were confirmed by electron microscopy and by the production of intracellular reactive oxygen species (Phillips et al., (a)
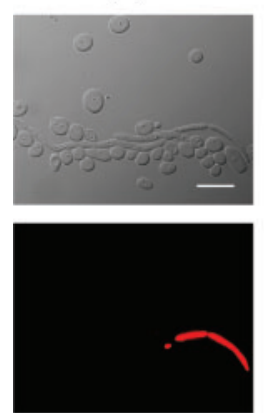

(b)
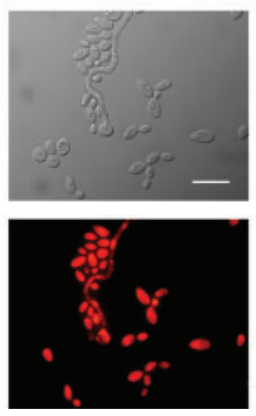

(c)
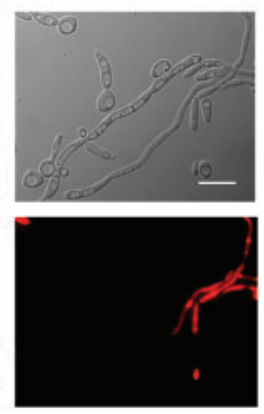

(d)
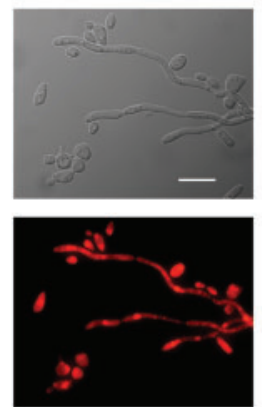

(e)
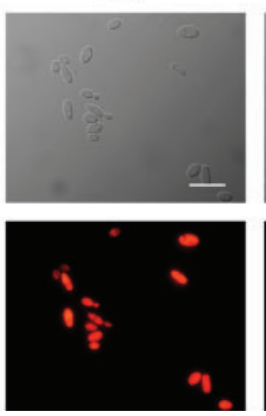

(f)

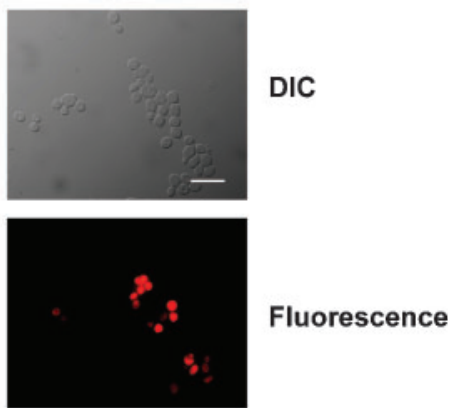

Fig. 2. Caspase detection using a polycaspase SR-FLICA reagent. Biofilms ( $48 \mathrm{~h})$ were incubated with amphotericin $B(50 \mu \mathrm{g}$ $\mathrm{ml}^{-1}$ ) for 5 or $24 \mathrm{~h}$ at $37{ }^{\circ} \mathrm{C}$. Washed, resuspended biofilm cells were then labelled with the SR-FLICA reagent and examined by fluorescence microscopy. DIC and fluorescence images are shown of C. albicans GDH 2346 exposed to amphotericin B for $5 \mathrm{~h}$ (a) and 24 h (b); C. albicans SC5314 exposed to amphotericin B for 5 h (c) and 24 h (d); C. krusei exposed to amphotericin B for $24 \mathrm{~h} \mathrm{(e);} \mathrm{and} \mathrm{C.} \mathrm{parapsilosis} \mathrm{exposed} \mathrm{to} \mathrm{amphotericin} \mathrm{B} \mathrm{for} 24 \mathrm{~h}$ (f). Caspase activity is indicated by orange/ red fluorescence. Bars, $13 \mu \mathrm{m}$. 
2003). The benefits of such a suicide process to unicellular organisms like yeasts are not immediately obvious. However, apoptosis could be highly advantageous for a biofilm community that, in many ways, resembles a multicellular organism. The self-destruction of damaged cells that consume scarce nutrients in a vain attempt to repair themselves could enhance the viability and reproductive success of healthier members of the community (Buttner et al., 2006; Lewis, 2000).

Although FLICAs have become widely employed for the detection of active caspases in yeasts as well as in mammalian cells, their use has sometimes been controversial (Pozarowski et al., 2003; Vachova \& Palkova, 2007). Madeo et al. (2002) reported FLICA binding to active caspase in intact (propidium iodide negative) cells of $S$. cerevisiae, and only in cells containing a functional YCA1 gene; no binding was detected in a ycal mutant. However, other studies have indicated non-specific FLICA binding by heat-killed or ageing yeast cells (Vachova \& Palkova, 2007; Wysocki \& Kron, 2004). In the present investigation, fluorescent staining was rarely observed in control cells from biofilms not exposed to amphotericin B. Moreover, caspase activity, as detected by FLICA, increased with longer incubation times. However, to demonstrate unequivocally caspase activity in drug-treated biofilm cells, a second staining method, utilizing a $\mathrm{D}_{2} \mathrm{R}$ reagent, was also used.

\section{Caspase detection using a $D_{2} R$ reagent}

This assay is based on the cleavage of $D_{2} R$, which is a substrate for caspases. $\mathrm{D}_{2} \mathrm{R}$ is non-fluorescent, but when cleaved by caspases it releases green fluorescent monosubstituted rhodamine 110 and free rhodamine. This method therefore allows only the detection of active caspases and so avoids the artefactual, non-specific staining that has been reported in some cases with the FLICA reagent (Vachova \& Palkova, 2007). For biofilms exposed to amphotericin $\mathrm{B}$, the number of cells stained by $\mathrm{D}_{2} \mathrm{R}$ was high (96\%; Fig. 3); cells from untreated biofilms, however, were rarely stained. These results confirm those obtained with the FLICA assay and indicate that drug-treated biofilm cells undergo apoptosis. Recently, two separate research groups have demonstrated caspase activity in planktonic cultures of $C$. albicans using the $\mathrm{D}_{2} \mathrm{R}$ or FLICA reagent (Cao et al., 2009; Shirtliff et al., 2009).

\section{General caspase inhibitor Z-VAD-FMK decreases the activity of amphotericin B against Candida biofilms}

Mature (48 h) biofilms of C. albicans GDH 2346, C. krusei and C. parapsilosis were incubated for $24 \mathrm{~h}$ at $37^{\circ} \mathrm{C}$ in fresh growth medium in the presence of different concentrations (2.5 to $20 \mu \mathrm{M})$ of Z-VAD-FMK, which is active against a range of caspases. Addition of this inhibitor had no significant effect on biofilm viability of any of the three species at any concentration tested (results not shown). However, when Z-VAD-FMK was added at low concentration $(2.5 \mu \mathrm{M})$ together with amphotericin $\mathrm{B}(50 \mu \mathrm{g}$ $\mathrm{ml}^{-1}$ ), it significantly reduced the effect of the drug on Candida biofilms. Biofilm viability was increased 11.5 -fold $(P<0.001)$ and 1.6 -fold $(P<0.05)$ for $C$. albicans and $C$. parapsilosis, respectively, in the presence of both compounds (Fig. 4), although there was no significant increase in viability with $C$. krusei biofilms. In contrast, high concentrations (10 to $20 \mu \mathrm{M}$ ) of Z-VAD-FMK were ineffective at preventing cell death and instead appeared to enhance it (Fig. 4).

The effect of combined treatment with Z-VAD-FMK and amphotericin B was also investigated with biofilms of $C$. albicans SC5314. This strain appears to lack persisters, and biofilms lose all viability after exposure to amphotericin B at $30 \mu \mathrm{g} \mathrm{ml}^{-1}$ (Al-Dhaheri \& Douglas, 2008). When $48 \mathrm{~h}$ biofilms were treated with Z-VAD-FMK $(2.5 \mu \mathrm{M})$ and (a)
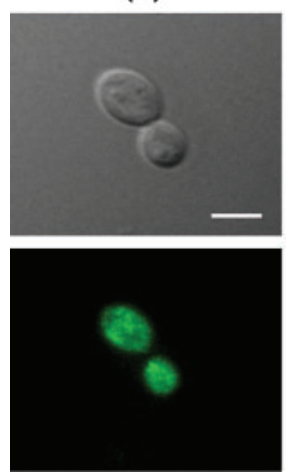

(b)
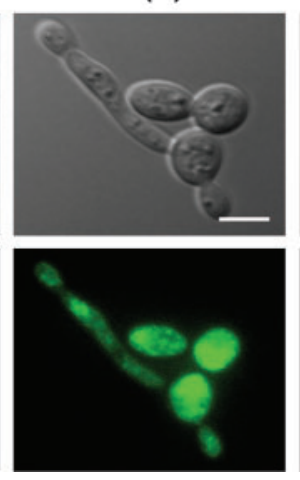

(c)
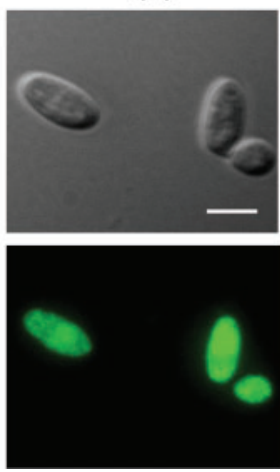

(d)

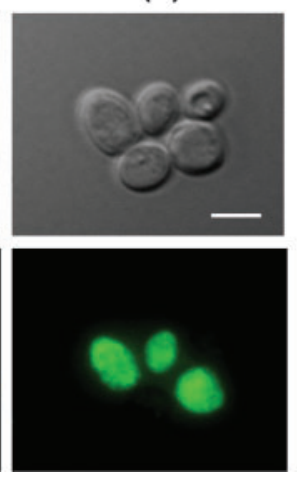

DIC

Fluorescence

Fig. 3. Caspase detection using $D_{2} R$ reagent. Biofilms (48 h) were incubated with amphotericin $B\left(50 \mu g \mathrm{ml}^{-1}\right)$ for $24 \mathrm{~h}$ at $37{ }^{\circ} \mathrm{C}$. Washed, resuspended biofilm cells were then labelled with the $\mathrm{D}_{2} \mathrm{R}$ reagent and examined by fluorescence microscopy. DIC and fluorescence images are shown of C. albicans GDH 2346 (a), C. albicans SC5314 (b), C. krusei (c) and C. parapsilosis (d). Caspase activity is indicated by green fluorescence. Bars, $5 \mu \mathrm{m}$. 


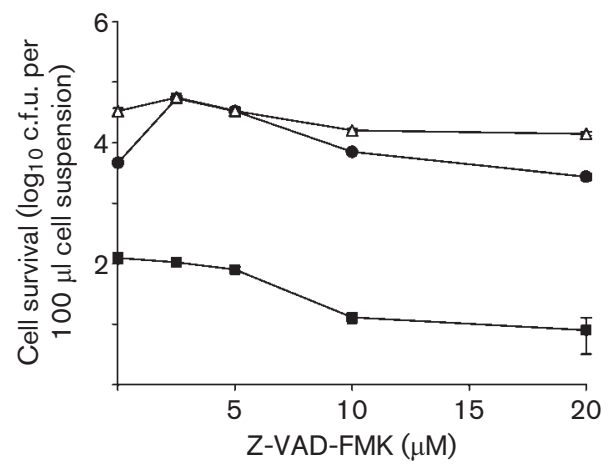

Fig. 4. Effect of general caspase inhibitor Z-VAD-FMK on amphotericin B activity against biofilms of C. albicans GDH 2346 ( ), C. parapsilosis $(\triangle)$ and C. krusei ( $\boldsymbol{\square})$. Biofilms (48 h) were incubated with Z-VAD-FMK and amphotericin B $\left(50 \mu \mathrm{g} \mathrm{ml}^{-1}\right)$ for $24 \mathrm{~h}$ at $37{ }^{\circ} \mathrm{C}$ and cell survival was determined by viable cell counts. Results are shown as means \pm SES of two independent experiments carried out in duplicate.

amphotericin B $\left(50 \mu \mathrm{g} \mathrm{ml}^{-1}\right)$ for $24 \mathrm{~h}$ at $37{ }^{\circ} \mathrm{C}$, there was a complete loss of viability like that observed with control biofilms exposed only to the antifungal agent. However, biofilms treated with Z-VAD-FMK and a lower concentration $\left(10 \mu \mathrm{g} \mathrm{ml}^{-1}\right)$ of amphotericin B showed an 11.9fold increase in viability $(P<0.001)$.

The specificity of the effect noted with the general caspase inhibitor was investigated using pepstatin A, an inhibitor of aspartic proteinases, which are known to be produced by Candida species. Exposure of $48 \mathrm{~h}$ biofilms of either $C$. albicans strain to amphotericin B $\left(50 \mu \mathrm{g} \mathrm{ml} \mathrm{ml}^{-1}\right)$ and pepstatin $\mathrm{A}(2.5 \mu \mathrm{M})$ for $24 \mathrm{~h}$ at $37^{\circ} \mathrm{C}$ did not significantly affect cell survival (results not shown).

\section{Some specific caspase inhibitors decrease the activity of amphotericin B against C. albicans biofilms}

A set of specific caspase inhibitors, active individually against caspases- $1,-2,-3,-5,-6,-8$ and -9 , was also tested against $C$. albicans biofilms. Again, none of these inhibitors affected biofilm viability when incubated at $2.5 \mu \mathrm{M}$ with $48 \mathrm{~h}$ biofilms of C. albicans GDH 2346 for $24 \mathrm{~h}$ at $37{ }^{\circ} \mathrm{C}$ (results not shown). However, when added to biofilms along with amphotericin B, some of the inhibitors significantly enhanced the survival of biofilm cells as compared with controls treated with only the antifungal drug. Caspase-1 inhibitor VI produced a 40-fold increase in biofilm cell survival $(P<0.001)$ compared with amphotericin-treated controls (Fig. 5). Similarly, inhibitors of caspases-9, $-5,-3$ and -2 increased cell survival 8 -fold $(P<0.001)$, 3.5-fold $(P<0.001)$, 1.9-fold $(P<0.001)$ and 1.7 -fold $(P<0.01)$, respectively. In contrast, caspase- 6 and caspase- 8 inhibitors decreased biofilm cell survival as compared with the amphotericin-treated controls (Fig. 5).

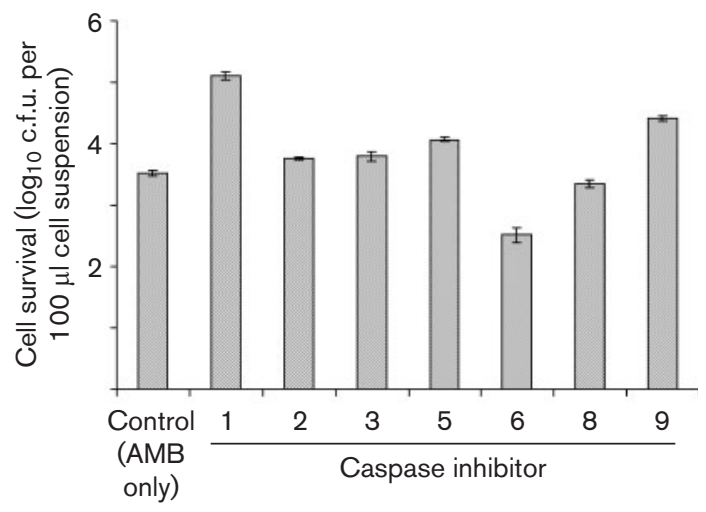

Fig. 5. Effects of specific inhibitors of caspases-1, $-2,-3,-5,-6,-8$ and -9 on amphotericin $B$ activity against biofilms of $C$. albicans $\mathrm{GDH}$ 2346. Biofilms $(48 \mathrm{~h})$ were incubated with inhibitor $(2.5 \mu \mathrm{M})$ and amphotericin $\mathrm{B}\left(50 \mu \mathrm{g} \mathrm{ml}^{-1}\right)$ for $24 \mathrm{~h}$ at $37{ }^{\circ} \mathrm{C}$, and cell survival was determined by viable cell counts. Results are shown as means \pm SES of two independent experiments carried out in duplicate.

Partial suppression of caspase activity in C. albicans by mammalian caspase inhibitors is not wholly unexpected. To date, only one enzyme with caspase-like activity, CaMCA1, has been identified in C. albicans. This, like its homologue in S. cerevisiae, YCA1/MCA1, is a metacaspase (Cao et al., 2009). Mammalian caspases are cysteine proteases with a stringent specificity for cleaving protein substrates containing aspartic acid. Plant, protozoan and fungal metacaspases, however, display arginine and lysine protease specificity instead of the aspartic acid specificity characteristic of caspases. Nevertheless, Madeo et al. (2002) reported that extracts of a YCA1 overproducing strain of $S$. cerevisiae, which had been treated with $\mathrm{H}_{2} \mathrm{O}_{2}$ to induce apoptosis, showed a high proteolytic activity towards several substrates for mammalian caspases. Addition of the general caspase inhibitor, Z-VAD-FMK, to the extracts completely abrogated this catalytic activity. Mammalian caspase inhibitors, including Z-VAD-FMK, are also known to be remarkably efficient at blocking programmed cell death in plants (Bonneau et al., 2008). However, there is some evidence that plant metacaspases do not cleave caspase substrates and are not inhibited by caspase inhibitors (Bonneau et al., 2008). It is therefore possible that other caspase-like activities are present in both plants and yeasts. In $S$. cerevisiae, for example, an MCA1/YCA1independent caspase-like activity has been detected in an mcal mutant using the $\mathrm{D}_{2} \mathrm{R}$ staining procedure (Vachova \& Palkova, 2005). There are several other reports of MCA1independent caspase-like activities in S. cerevisiae detected by different approaches (Vachova \& Palkova, 2007).

\section{HDA inhibitors enhance the activity of amphotericin B against Candida biofilms}

Mature (48 h) biofilms of C. albicans GDH 2346, C. krusei and C. parapsilosis were incubated for $24 \mathrm{~h}$ at $37{ }^{\circ} \mathrm{C}$ in fresh 
growth medium in the presence of four different HDA inhibitors, namely sodium butyrate, sodium valproate, apicidin and trichostatin A. None of these compounds affected the viability of any of the species when tested at concentrations ranging from 2 to $32 \mu \mathrm{g} \mathrm{ml}^{-1}$, or 2 to $32 \mathrm{mM}$ (equivalent to $220 \mu \mathrm{g} \mathrm{ml}^{-1}$ to $3.52 \mathrm{mg} \mathrm{ml}^{-1}$, for sodium butyrate) (results not shown). However, when the inhibitors were added to biofilms concurrently with amphotericin B, there was a marked effect on viability (Fig. 6). Biofilm populations of $C$. albicans were completely eliminated by sodium butyrate $(8$ or $32 \mathrm{mM})$ at low concentrations of amphotericin B (10 $\mu \mathrm{g} \mathrm{ml}^{-1}$; Fig. 6a), and by even lower concentrations of butyrate $(2 \mathrm{mM})$ at higher concentrations $\left(50 \mu \mathrm{g} \mathrm{ml}^{-1}\right)$ of the drug (Fig. 6b). In the absence of butyrate, biofilms of this strain of $C$. albicans produce persisters that remain viable at amphotericin $\mathrm{B}$ concentrations of up to $100 \mu \mathrm{g} \mathrm{ml}^{-1}$ (Al-Dhaheri \& Douglas, 2008). Biofilms of $C$. krusei and C. parapsilosis, which also produce persisters, were rather less susceptible; combined treatment with butyrate $(32 \mathrm{mM})$ and amphotericin B $\left(50 \mu \mathrm{g} \mathrm{ml}^{-1}\right)$ reduced biofilm viability by 66 and $75 \%$, respectively (Fig. 6c, d).

A second HDA inhibitor, sodium valproate, also effectively eliminated biofilm populations of C. albicans when used at a concentration of $32 \mu \mathrm{g} \mathrm{ml}^{-1}$ with amphotericin B at $50 \mu \mathrm{g} \mathrm{ml}^{-1}$ (Fig. 6b). Biofilms of C. krusei were even more sensitive to this inhibitor and lost all viability after treatment with $8 \mu \mathrm{g}$ valproate $\mathrm{ml}^{-1}$ and $50 \mu \mathrm{g}$ amphotericin $\mathrm{B} \mathrm{ml}^{-1}$ (Fig. 6c). However, biofilms of C. parapsilosis lost only $43 \%$ of their viability when treated in an identical manner (Fig. 6d).

The other HDA inhibitors, apicidin and trichostatin A, both significantly reduced biofilm viability of all species tested $(P<0.002)$ when used in conjunction with amphotericin B (Fig. 6), although neither inhibitor produced complete killing of the biofilm population. Trichostatin A was not tested against $C$. albicans since it was noted that this inhibitor used in combination with amphotericin $B$ caused some detachment of $C$. albicans biofilms from polyvinyl chloride discs.

HDA inhibitors are known to induce apoptosis in mammalian cells (Kawagoe et al., 2002; Medina et al., 1997). Recently, valproate was reported to induce YCA1dependent apoptosis in S. cerevisiae; a ycal mutant survived this treatment (Mitsui et al., 2005). It was subsequently shown that valproate also stimulated the accumulation of neutral lipids, mainly triacylglycerol, in

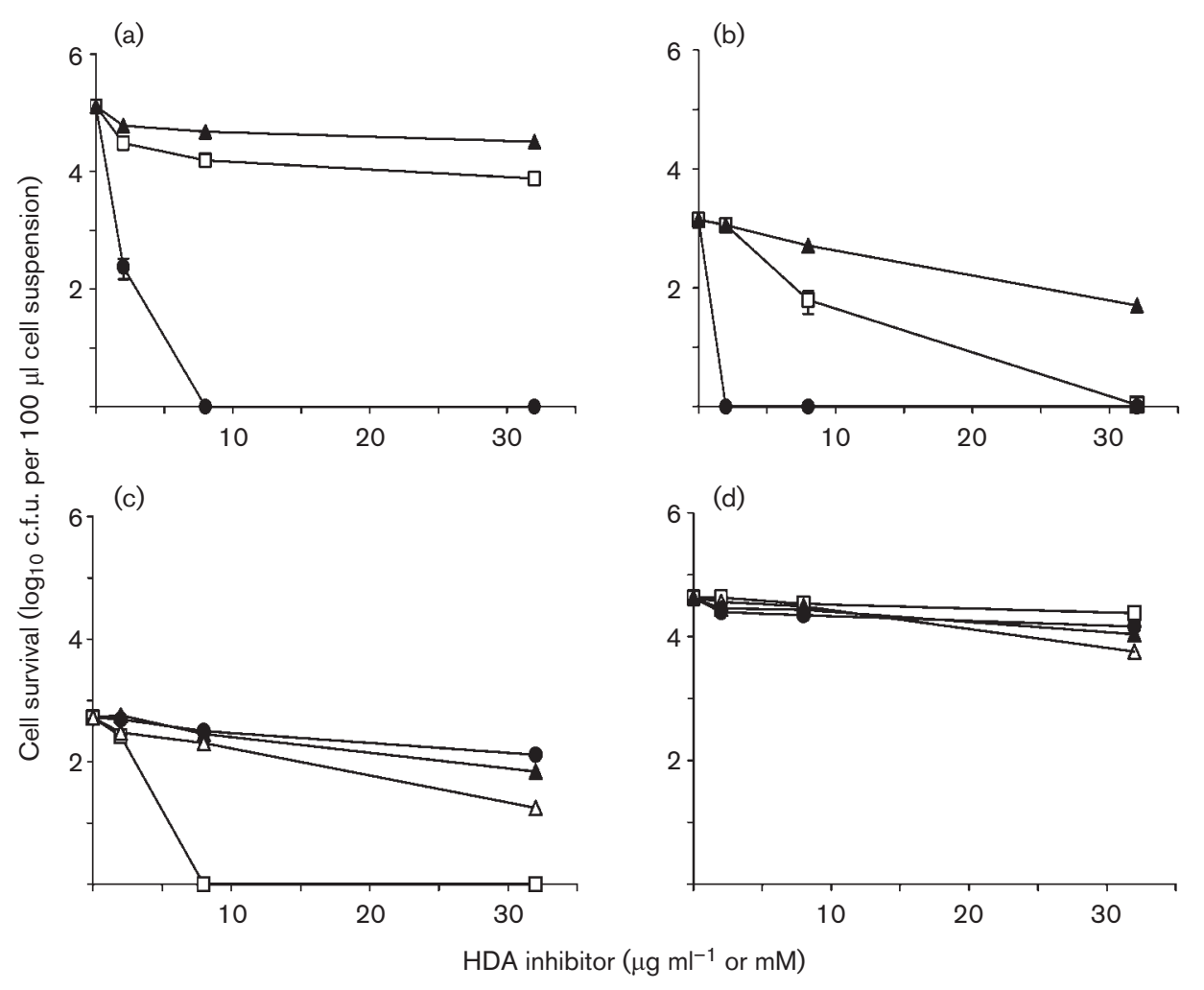

Fig. 6. Effects of HDA inhibitors on amphotericin B activity against biofilms of C. albicans GDH 2346 (a, b), C. krusei (c) and C. parapsilosis (d). Biofilms (48 h) were incubated with amphotericin B at concentrations of $10 \mu \mathrm{g} \mathrm{ml}^{-1}$ (a) or $50 \mu \mathrm{g} \mathrm{ml}^{-1}(\mathrm{~b}, \mathrm{c}$, d), and sodium butyrate $(\bullet ; \mathrm{mM})$, sodium valproate $\left(\square ; \mu \mathrm{g} \mathrm{ml}^{-1}\right)$, apicidin $\left(\boldsymbol{\Delta} ; \mu \mathrm{g} \mathrm{ml}^{-1}\right)$ or trichostatin $\mathrm{A}\left(\triangle ; \mu \mathrm{g} \mathrm{ml^{-1 }}\right)$. After $24 \mathrm{~h}$ at $37{ }^{\circ} \mathrm{C}$, cell survival was determined by viable cell counts. Results are shown as means \pm SEs of two independent experiments carried out in duplicate. 
the apoptotic wild-type cells (Sun et al., 2007). Valproic acid is a short-chain fatty acid widely used in humans as an anticonvulsant, and has teratogenic and anti-tumour activities. Whether it induces lipid accumulation in $C$. albicans is not known. Sodium butyrate was even more effective than valproate at eradicating biofilms of $C$. albicans GDH 2346 when added to incubation mixtures together with amphotericin B. Butyrate inhibits germination in C. albicans (Noverr \& Huffnagle, 2004); at concentrations of 4 to $8 \mathrm{mM}$, it also enhances the activity of fluconazole against planktonic C. albicans cells (Smith \& Edlind, 2002).

Drug-tolerant persisters capable of withstanding high concentrations of amphotericin $\mathrm{B}$ have been detected in biofilms of many but not all strains of C. albicans tested. Biofilms of C. albicans SC5314, for example, appear to lack persisters, as demonstrated here by fluorescein staining, and previously by viable counts (Al-Dhaheri \& Douglas, 2008). Similarly, while biofilms of C. krusei and C. parapsilosis produce persisters, biofilms of some strains of C. glabrata and C. tropicalis do not (Al-Dhaheri \& Douglas, 2008). The reasons for these differences are not clear. Moreover, the mechanisms by which Candida persisters tolerate high drug concentrations are not understood. This investigation has demonstrated that persisters capable of surviving amphotericin B concentrations of $100 \mu \mathrm{g} \mathrm{ml}^{-1}$ are nevertheless eradicated at lower drug concentrations when simultaneously subjected to an HDA inhibitor such as valproate or butyrate. On the basis of this finding it can be inferred that histone acetylation might somehow activate apoptosis in these cells. The HDA inhibitor, trichostatin A, is known to affect colony-type phenotypic switching in $C$. albicans. It causes a dramatic increase in the frequency of switching in the white-to-opaque transition but has no effect on the frequency of switching in the opaque-to-white transition, suggesting that deacetylation through a trichostatin-sensitive deacetylase selectively suppresses switching in one direction (Klar et al., 2001). Targeted deletion of HDA1, which encodes a deacetylase sensitive to trichostatin A, had the same selective effect. Subsequent studies showed that a second HDA gene, RPD3, plays a role in suppressing the basic switch events in both directions (Srikantha et al., 2001). Whether these or any other HDA genes are involved in the regulation of caspase-like activity in C. albicans biofilms remains to be demonstrated.

Trichostatin A and other HDA inhibitors have also been shown to enhance the sensitivity of planktonic C. albicans to the azoles fluconazole, itraconazole and miconazole. Smith \& Edlind (2002) reported that expression of ERG genes (encoding azole targets) and CDR/MDR1 genes (encoding multidrug transporters) was induced by fluconazole, but that trichostatin A reduced this upregulation by 50 to $100 \%$. The authors concluded that trichostatin A probably does not act directly on ERG and CDR gene promoters since decreased deacetylation (i.e. increased acetylation) should enhance, not inhibit, transcriptional upregulation. Rather, azole treatment could be associated with histone deacetylation of the promoter region of a transcriptional repressor. The resulting downregulation of this repressor would lead to upregulation of $E R G$ and $C D R$. However, HDA inhibition by trichostatin A would result in constitutive expression of this repressor, blocking ERG/ CDR upregulation (Smith \& Edlind, 2002).

Recent evidence suggests that the Ras-cAMP-PKA signalling pathway in C. albicans regulates programmed cell death induced by exposure to acetic acid or hydrogen peroxide, either by inhibiting antiapoptotic functions (such as stress responses) or by activating proapoptotic functions (Phillips et al., 2006). Mutations that block Ras signalling were shown to suppress or delay the apoptotic response; in contrast, mutations that stimulate signalling accelerated the apoptotic response. The role of histone acetylation or deacetylation, if any, in this regulatory process is not known, nor is it clear whether the Ras pathway is involved in amphotericin-induced apoptosis either in planktonic or in biofilm cultures. However, treatment of $C$. albicans with trichostatin A has been reported to produce a significant reduction in transcription of EFG1, a gene that encodes a key regulatory protein in this pathway (Simonetti et al., 2007). Studies with biofilms of Ras mutants of C. albicans could therefore be instructive and might help to elucidate the mechanism by which drug-tolerant persisters resist programmed cell death.

\section{ACKNOWLEDGEMENTS}

Rawya Al-Dhaheri is the recipient of a research studentship from the Health Authority, Abu Dhabi, United Arab Emirates. We are indebted to Andrew Roe for expert assistance with fluorescence microscopy.

\section{REFERENCES}

Al-Dhaheri, R. S. \& Douglas, L. J. (2008). Absence of amphotericin Btolerant persister cells in biofilms of some Candida species. Antimicrob Agents Chemother 52, 1884-1887.

Baillie, G. S. \& Douglas, L. J. (1999). Candida biofilms and their susceptibility to antifungal agents. Methods Enzymol 310, 644-656.

Bonneau, L., Ge, Y., Drury, G. E. \& Gallois, P. (2008). What happened to plant caspases? J Exp Bot 59, 491-499.

Buttner, S., Eisenberg, T., Herker, E., Carmona-Gutierrez, D., Kroemer, G. \& Madeo, F. (2006). Why yeast cells can undergo apoptosis: death in times of peace, love, and war. J Cell Biol 175, 521525.

Cao, Y. Y., Huang, S., Dai, B. D., Zhu, Z. Y., Lu, H., Dong, L. L., Cao, Y. B., Wang, Y., Gao, P. H. \& other authors (2009). Candida albicans cells lacking CaMCA1-encoded metacaspase show resistance to oxidative stress-induced death and change in energy metabolism. Fungal Genet Biol 46, 183-189.

Choi, H. W., Shin, J. H., Jung, S. I., Park, K. H., Cho, D., Kee, S. J., Shin, M. G., Suh, S. P. \& Ryang, D. W. (2007). Species-specific differences in the susceptibilities of biofilms formed by Candida bloodstream isolates to echinocandin antifungals. Antimicrob Agents Chemother 51, $1520-1523$.

Douglas, L. J. (2003). Candida biofilms and their role in infection. Trends Microbiol 11, 30-36. 
Hamann, A., Brust, D. \& Osiewacz, H. D. (2008). Apoptosis pathways in fungal growth, development and ageing. Trends Microbiol 16, 276283.

Hawser, S. P. \& Douglas, L. J. (1994). Biofilm formation by Candida species on the surface of catheter materials in vitro. Infect Immun 62, 915-921.

Hawser, S. P. \& Douglas, L. J. (1995). Resistance of Candida albicans biofilms to antifungal agents in vitro. Antimicrob Agents Chemother 39, 2128-2131.

Katragkou, A., Chatzimoschou, A., Simitsopoulou, M., Dalakiouridou, M., Diza-Mataftsi, E., Tsantali, C. \& Roilides, E. (2008). Differential activities of newer antifungal agents against Candida albicans and Candida parapsilosis biofilms. Antimicrob Agents Chemother 52, 357-360.

Kawagoe, R., Kawagoe, H. \& Sano, K. (2002). Valproic acid induces apoptosis in human leukemia cells by stimulating both caspasedependent and -independent apoptotic signaling pathways. Leuk Res 26, 495-502.

Keren, I., Kaldalu, N., Spoering, A., Wang, Y. \& Lewis, K. (2004). Persister cells and tolerance to antimicrobials. FEMS Microbiol Lett 230, 13-18.

Khot, P. D., Suci, P. A., Miller, R. L., Nelson, R. D. \& Tyler, B. J. (2006). A small subpopulation of blastospores in Candida albicans biofilms exhibit resistance to amphotericin B associated with differential regulation of ergosterol and $\beta$-1,6-glucan pathway genes. Antimicrob Agents Chemother 50, 3708-3716.

Klar, A. J., Srikantha, T. \& Soll, D. R. (2001). A histone deacetylation inhibitor and mutant promote colony-type switching of the human pathogen Candida albicans. Genetics 158, 919-924.

Kojic, E. M. \& Darouiche, R. O. (2004). Candida infections of medical devices. Clin Microbiol Rev 17, 255-267.

LaFleur, M. D., Kumamoto, C. A. \& Lewis, K. (2006). Candida albicans biofilms produce antifungal-tolerant persister cells. Antimicrob Agents Chemother 50, 3839-3846.

Lewis, K. (2000). Programmed cell death in bacteria. Microbiol Mol Biol Rev 64, 503-514.

Lewis, K. (2001). Riddle of biofilm resistance. Antimicrob Agents Chemother 45, 999-1007.

Lewis, K. (2007). Persister cells, dormancy and infectious disease. Nat Rev Microbiol 5, 48-56.

Madeo, F., Herker, E., Maldener, C., Wissing, S., Lachelt, S., Herlan, M., Fehr, M., Lauber, K., Sigrist, S. J. \& other authors (2002). A caspaserelated protease regulates apoptosis in yeast. Mol Cell 9, 911-917.

Mai, A., Rotili, D., Massa, S., Brosch, G., Simonetti, G., Passariello, C. \& Palamara, A. T. (2007). Discovery of uracil-based histone deacetylase inhibitors able to reduce acquired antifungal resistance and trailing growth in Candida albicans. Bioorg Med Chem Lett 17, $1221-1225$.

Mazzoni, C. \& Falcone, C. (2008). Caspase-dependent apoptosis in yeast. Biochim Biophys Acta 1783, 1320-1327.

Medina, V., Edmonds, B., Young, G. P., James, R., Appleton, S. \& Zalewski, P. D. (1997). Induction of caspase-3 protease activity and apoptosis by butyrate and trichostatin A (inhibitors of histone deacetylase): dependence on protein synthesis and synergy with a mitochondrial/cytochrome c-dependent pathway. Cancer Res 57, 3697-3707.
Mitsui, K., Nakagawa, D., Nakamura, M., Okamoto, T. \& Tsurugi, K. (2005). Valproic acid induces apoptosis dependent of Ycalp at concentrations that mildly affect the proliferation of yeast. FEBS Lett 579, 723-727.

Noverr, M. C. \& Huffnagle, G. B. (2004). Regulation of Candida albicans morphogenesis by fatty acid metabolites. Infect Immun $\mathbf{7 2}$, 6206-6210.

Phillips, A. J., Sudbery, I. \& Ramsdale, M. (2003). Apoptosis induced by environmental stresses and amphotericin B in Candida albicans. Proc Natl Acad Sci U S A 100, 14327-14332.

Phillips, A. J., Crowe, J. D. \& Ramsdale, M. (2006). Ras pathway signaling accelerates programmed cell death in the pathogenic fungus Candida albicans. Proc Natl Acad Sci U S A 103, 726-731.

Pozarowski, P., Huang, X., Halicka, D. H., Lee, B., Johnson, G. \& Darzynkiewicz, Z. (2003). Interactions of fluorochrome-labeled caspase inhibitors with apoptotic cells: a caution in data interpretation. Cytometry A 55, 50-60.

Ramage, G., Saville, S. P., Thomas, D. P. \& Lopez-Ribot, J. L. (2005). Candida biofilms: an update. Eukaryot Cell 4, 633-638.

Ramsdale, M. (2008). Programmed cell death in pathogenic fungi. Biochim Biophys Acta 1783, 1369-1380.

Shirtliff, M. E., Krom, B. P., Meijering, R. A., Peters, B. M., Zhu, J., Scheper, M. A., Harris, M. L. \& Jabra-Rizk, M. A. (2009). Farnesolinduced apoptosis in Candida albicans. Antimicrob Agents Chemother 53, 2392-2401.

Simonetti, G., Passariello, C., Rotili, D., Mai, A., Garaci, E. \& Palamara, A. T. (2007). Histone deacetylase inhibitors may reduce pathogenicity and virulence in Candida albicans. FEMS Yeast Res 7, 1371-1380.

Smith, W. L. \& Edlind, T. D. (2002). Histone deacetylase inhibitors enhance Candida albicans sensitivity to azoles and related antifungals: correlation with reduction in $C D R$ and $E R G$ upregulation. Antimicrob Agents Chemother 46, 3532-3539.

Srikantha, T., Tsai, L., Daniels, K., Klar, A. J. S. \& Soll, D. R. (2001). The histone deacetylase genes HDA1 and RPD3 play distinct roles in regulation of high-frequency phenotypic switching in Candida albicans. J Bacteriol 183, 4614-4625.

Sterner, D. E. \& Berger, S. L. (2000). Acetylation of histones and transcription-related factors. Microbiol Mol Biol Rev 64, 435-459.

Sun, Q., Bi, L., Su, X., Tsurugi, K. \& Mitsui, K. (2007). Valproate induces apoptosis by inducing accumulation of neutral lipids which was prevented by disruption of the SIR2 gene in Saccharomyces cerevisiae. FEBS Lett 581, 3991-3995.

Uren, A. G., O'Rourke, K., Aravind, L., Pisabarro, M. T., Seshagiri, S., Koonin, E. V. \& Dixit, V. M. (2000). Identification of paracaspases and metacaspases: two ancient families of caspase-like proteins, one of which plays a key role in MALT lymphoma. Mol Cell 6, 961-967.

Vachova, L. \& Palkova, Z. (2005). Physiological regulation of yeast cell death in multicellular colonies is triggered by ammonia. J Cell Biol 169, 711-717.

Vachova, L. \& Palkova, Z. (2007). Caspases in yeast apoptosis-like death: facts and artefacts. FEMS Yeast Res 7, 12-21.

Wysocki, R. \& Kron, S. J. (2004). Yeast cell death during DNA damage arrest is independent of caspase or reactive oxygen species. J Cell Biol 166, 311-316. 